\title{
Training in the Management of
} Psychobehavioral Conditions: A Needs Assessment Survey of Emergency Medicine \section{Residents}

Jason Pickett, $\mathrm{MD}^{1}$, Mary Rose Calderone Haas, $\mathrm{MD}^{2}$, Megan L. Fix, MD², Ramin R. Tabatabai, MD ${ }^{4}$, Angela Carrick, $\mathrm{DO}^{5}$, Jennifer Robertson, $\mathrm{MD}^{6}$, Angelica Veronica Barnes, $\mathrm{MD}^{6}$, Amy Ondeyka, $\mathrm{MD}^{7}$, Mary Jane Brown, $\mathrm{MD}^{8}$, Andrew R. Edwards, $\mathrm{MD}^{9}$, and Erin Dehon, $\mathrm{PhD}^{1}$ (D)

\section{ABSTRACT}

Objective: Mental health-related ED visits are increasing. Despite this trend, most emergency medicine (EM) residency programs devote little time to psychiatry education. This study aimed to identify EM residents' perceptions of training needs in emergency psychiatry and self-confidence in managing patients with psychobehavioral conditions.

Methods: A needs assessment survey was distributed to residents at 15 Accreditation Council for Graduate Medical Education-accredited EM programs spanning the U.S. Survey items addressed amount and type of training in psychiatry during residency, perceived training needs in psychiatry, and self-confidence performing various clinical skills related to emergency psychiatric care. Residents used a 5-point scale $(1=$ nothing; $5=$ very large amount) to rate their learning needs in a variety of topic areas related to behavioral emergencies (e.g., medically clearing patients, substance use disorders). Using a scale from 0 to 100, residents rated their confidence in their ability to independently perform various clinical skills related to emergency psychiatric care (e.g., differentiating a psychiatric presentation from delirium).

Results: Of the 632 residents invited to participate, 396 (63\%) responded. Twelve percent of respondents reported completing a psychiatry rotation during EM residency. One of the 15 participating programs had a required psychiatry rotation. Residents reported that their program used lectures (56\%) and/or supervised training in the ED (35\%) to teach residents about psychiatric emergencies. Most residents reported minimal involvement in the treatment of patients with psychiatric concerns. The majority of residents (59\%) believed that their program should offer more education on managing psychiatric emergencies. Only $14 \%$ of residents felt "quite" or "extremely" prepared to treat psychiatric patients. Overall, residents reported the lowest levels of confidence and highest need for more training related to counseling suicidal patients and treating psychiatric issues in special populations (e.g., pregnant women, elderly, and children).

Conclusions: Most EM residents desire more training in managing psychiatric emergencies than is currently provided.

From the ${ }^{1}$ Department of Emergency Medicine, University of Mississippi Medical Center, Jackson, MS; the ${ }^{2}$ Department of Emergency Medicine, University of Michigan Medical School, Ann Arbor, MI; the ${ }^{3}$ Department of Emergency Medicine, University of Utah, Salt Lake City, UT; the ${ }^{4}$ Department of Emergency Medicine, School of Medicine of the University of Southern California, Los Angeles County + USC Medical Center, Los Angeles, CA; the ${ }^{5}$ Department of Emergency Medicine, Norman Regional Health System, Norman, OK; the ${ }^{6}$ Department of Emergency Medicine, Emory University School of Medicine, Atlanta, GA; the ${ }^{7}$ Department of Emergency Medicine, Inspira Health Network, Vineland, NJ; the ${ }^{8}$ Department of Emergency Medicine, University of Tennessee Health Science Center, Nashville, TN; and the ${ }^{9}$ Department of Emergency Medicine, University of Alabama at Birmingham, Birmingham, AL.

Received April 5, 2019; revision received June 19, 2019; accepted July 1, 2019.

The authors have no relevant financial information or potential conflicts to disclose.

Supervising Editor: Jason Wagner, MD.

Address for correspondence and reprints: Erin Dehon, PhD; e-mail: edehon@umc.edu.

AEM EDUCATION AND TRAINING 2019;3:365-374. 
$\mathrm{M}$ ental health $(\mathrm{MH})$ and substance use disorders (SUD) affect an estimated 43.6 million and 21.5 million adults, respectively, in the United States each year. ${ }^{1}$ Emergency departments (EDs) nationwide are increasingly providing care for individuals with $\mathrm{MH}$ and SUD. In 2007, approximately one in eight ED visits were related to a $\mathrm{MH}$ and/or SUD. ${ }^{2}$ More recent data show a $44.1 \%$ increase in $\mathrm{MH}$ and SUD visits to the ED between 2006 and $2014 .^{3}$ The overall rate of $\mathrm{ED}$ visits related to behavioral/MH concerns is increasing at a significantly faster rate than ED visits related to injuries or medical conditions. ${ }^{3}$ The increasing number of $\mathrm{MH}$-related visits combined with a national shortage of inpatient psychiatric beds have led to widespread boarding of psychiatric patients. Patients with primary psychobehavioral complaints have been found to wait 3.2 times longer for inpatient placement than patients with nonpsychiatric chief complaints. ${ }^{4}$ Given that EDs have become a main source of care for patients with $\mathrm{MH}$ complaints, it is important to identify whether EM residents are well prepared to meet this demand and treat these patients.

According to the American College of Emergency Physicians, "the practice of emergency medicine includes the initial evaluation, diagnosis, treatment coordination of care among multiple providers, and disposition of any patient requiring expeditious medical, surgical, or psychiatric care." 5 Currently, the 2018 Accreditation Council for Graduate Medical Education (ACGME) emergency medicine (EM) residency program requirements do not specify that programs ensure residents have ample experiences treating psychiatric patients. Instead, the ACGME states that "residents must demonstrate knowledge of established and evolving biomedical, clinical, epidemiological and social-behavioral sciences, as well as the application of this knowledge to patient care." ${ }^{6}$ The most recent version of the EM Model, the specialty's guiding document for curricula, includes the following conditions under psychobehavioral disorders as core content areas: SUD, mood disorders, thought disorders, factitious disorders, neurotic disorders, organic psychoses, patterns of violence/abuse/neglect, personality disorders, psychosomatic disorders, and feeding and eating disorders. ${ }^{7}$ The EM Model's section on procedures and skills integral to the practice of EM includes two components within the psychobehavioral category: psychiatric screening examination and violent patient management/restraint. ${ }^{7}$
Based on these guidelines, it appears that EM residents are expected to develop skills in treating psychobehavioral conditions through on-the-job training in the ED. This leaves EM programs with a wide array of variation and emphasis regarding the appropriate amount of education to EM residents in the area of psychobehavioral conditions. Although somewhat outdated, due to the paucity of literature in this area, one study from 2003 on the scope of psychiatric education provided by EM training programs showed that only $14 \%$ of the surveyed programs included a 1 -month psychiatry rotation and $67 \%$ of these programs did not provide or require any formal training in the acute management of psychobehavioral conditions. ${ }^{8}$ Additionally, EM residents have little incentive to study material related to $\mathrm{MH} / \mathrm{SUD}$ since only $4 \%$ of the questions on the American Board of Emergency Medicine Certification Exam pertain to psychobehavioral disorders. ${ }^{9}$ The importance of psychobehavioral disorders is also deemphasized in core EM textbooks (i.e., Tintinalli and Rosen) that allot only $2 \%$ to $3 \%$ of content to psychobehavioral disorders. ${ }^{10,11}$

There is limited research on EM residents perceived educational needs in managing psychobehavioral conditions. A survey conducted in 1988 among program directors of nonpsychiatric residencies (i.e., EM, family medicine, pediatrics, obstetrics-gynecology, and surgery) found a lack of training in emergency psychiatric interventions. ${ }^{12}$ However, this study is outdated and included only the program directors' perspectives. To begin to address these gaps in the literature, we conducted an educational needs assessment survey that aims to identify EM residents' self-perceived training needs and self-confidence in evaluating and treating patients with psychobehavioral conditions.

\section{METHODS}

\section{Study Design and Population}

We designed and distributed an anonymous and voluntary needs assessment survey to EM resident physicians at 15 ACGME-accredited EM residency programs across the United States from July 2018 to October 2018. We identified a geographically diverse sample of residency programs to participate through directed emails to program directors who serve on the Council of Emergency Medicine Residency Directors (CORD) Resilience Committee. The e-mail did not provide any incentive to participate. EM residents at these select residencies were surveyed using a self- 
administered internet or paper questionnaire. The results were then mailed or e-mailed back to our home institution. The study received institutional review board approval from the University of Mississippi Medical Center. Informed consent was waived to preserve participant anonymity.

\section{Survey Content and Administration}

The authors collaborated to create a survey instrument aimed to determine the breadth and depth of psychiatric education, both optional and required, provided by EM residency programs. The survey was modeled using similar formats to existing needs assessments surveys (i.e., Cook et al. ${ }^{13}$ ). Initial items were identified based on literature about the emergency physician's role in psychobehavioral emergencies. ${ }^{7,14}$ A list of potential items were reviewed, edited, and finalized by several of the authors, many of whom are members of the CORD Resilience Committee. Survey items asked EM residents to report their own levels of formal training in psychiatry, comfort treating psychiatric patients, and self-perceived training needs and self-confidence in 15 specific clinical skills related to psychiatric care. Items about demographic information were also included. Most items assessing residents self-perceived training needs and comfort treating psychiatric patients consisted of a 5-point unipolar response scale $(1=$ nothing or not at all comfortable; $5=$ very large amount or extremely comfortable). Residents also rated their confidence in their ability to independently perform various clinical skills related to psychobehavioral conditions (e.g., differentiating a psychiatric presentation from delirium, developing a safety plan with a suicidal patient) using a 100-point scale, ranging from 0 (cannot do at all) to 100 (highly certain can do). The use of a 0 to 100 scale was based on existing recommendations for developing confidence scales. ${ }^{15}$ Items can be seen in Tables 2 and 3 .

Finally, residents' attitudes toward individuals with mental illness was assessed using the Attitude Subscale of the Opening Minds Scale for Health Care Providers (i.e., Kassam et al. ${ }^{16}$ ) an instrument that measures providers' attitudes toward people with mental illness. Higher scores suggest a more stigmatizing attitude. Cronbach's alpha was 0.75. Items are listed in Table 4.

\section{Data Analysis}

Results were analyzed with IBM SPSS Statistics for Windows, Version 24.0. Descriptive statistics were used to analyze resident characteristics and survey responses. Analysis of variance was used to examine differences in self-perceived educational needs and confidence by postgraduate year (PGY) level.

\section{RESULTS}

\section{Characteristics of Participating Residents}

A total of 632 EM residents representing 15 programs and 12 different states were invited to complete the survey. Of those invited to participate, 396 residents completed the survey for a response rate of $62.7 \%$. The respondents were $59.8 \%$ male and $40.2 \%$ female and included a relatively equal breakdown of PGYs (Table 1).

\section{Characteristics of Participating Programs}

Response rate by institution ranged from 35\% to $50 \%$ $(3 / 15), 50 \%$ to $65 \%(3 / 15), 65 \%$ to $80 \%(5 / 15)$, and $>80 \%$ (3/15; see Data Supplement S1, available as supporting information in the online version of this paper, which is available at http://onlinelibrary.wiley.c om/doi/10.1002/aet2.10377/full, for a list of participating institutions and response rate by institution and PGY level). Eight of the programs used a 3-year training format, five programs used a 4-year format, and two programs were in the midst of transitioning from a 4-year to a 3-year program. Programs spanned all five regions of the U.S. One of the 15 programs had a required psychiatry rotation. Twelve of the 15 participating programs had a "psychiatrist available in real time to consult on ED patients 24 hours a day."

\section{Training in Psychiatry and Current Involvement in Psychiatric Emergencies}

Almost all of the resident participants (>99\%) reported that they completed a formal rotation in psychiatry in medical school. Overall, $12 \%$ of resident respondents reported completing a psychiatry rotation during their EM residency. The vast majority of these residents were attending a residency program that required a psychiatry rotation. Three residents from other programs reported that they opted to complete an elective psychiatry rotation. All residents reported seeing at least one to two patients with a psychiatric or behavioral complaint during a typical 8-hour ED shift. Although residents frequently evaluate patients with psychobehavioral conditions, over half (55\%) identified their level of involvement in managing these patients (beyond medical clearance) as "minimal" or "none." 


\begin{tabular}{lc}
\hline $\begin{array}{l}\text { Table } 1 \\
\text { Participant Demographics }\end{array}$ \\
\hline Participant Characteristics & $n(\%)^{\dagger}$ \\
\hline Sex & $232(59.8)$ \\
\hline Male & $156(40.2)$ \\
\hline Female & $137(34.8)$ \\
\hline Postgraduate year & $119(30.2)$ \\
\hline PGY-1 & $138(35.2)$ \\
\hline PGY-2 & $376(95.4)$ \\
\hline PGY- 3 & $3(0.8)$ \\
\hline Prior residency training & $15(3.8)$ \\
\hline No & $121(30.6)$ \\
\hline Yes & $94(23.7)$ \\
\hline Partially & $23(5.8)$ \\
\hline Region & $61(15.4)$ \\
\hline Northeast & $97(24.5)$ \\
\hline Southeast & $36(11.8)$ \\
\hline Southwest & $314(99.7)$ \\
\hline Midwest & $28(9.1)$ \\
\hline West & \\
\hline Completed a rotation in psychiatry & \\
\hline During residency & \\
\hline During medical school & \\
\hline Average number of patients with psychiatric chief complaints \\
\hline seen in a typical 8-hour shift
\end{tabular}

${ }^{\dagger}$ The number of respondents $(n)$ varies for categories due to missing data

Residents from institutions who did not have a psychiatrist available for consultation 24 hours a day reported similar levels of involvement as those who did have a psychiatry consultant available.

\section{Perceptions About Training in Psychiatry}

Sixty-nine percent of residents felt it is quite or extremely important to develop competency in the assessment and treatment of patients with psychobehavioral conditions. However, only $13 \%$ felt well prepared to assess and treat such patients, and a majority of residents $(59 \%)$ felt that their program should offer more training in managing psychobehavioral conditions. Residents who felt that their program should offer more training in managing psychobehavioral emergencies thought it should be delivered through a variety of formats including lectures (29\%), simulation exercises (26\%), supervised training in the ED (21\%), a core rotation (9\%), and an elective (13\%). Residents indicated that their programs currently provided education about psychobehavioral conditions through use of lectures (56\%), supervised training in the ED (35\%), and simulation (6\%). Six percent of residents reported having no formal education dedicated to management of patients with psychobehavioral conditions.

The majority of residents ( mean $=60 \%$ ) felt a need for at least "moderate improvement" in their clinical practice across 15 areas relevant to emergency psychiatric care. Overall, residents reported needing the least amount of training pertaining to medically clearing patients and the most amount of training pertaining to caring for special patient populations (e.g., children, elderly, and pregnant women). Verbatim wording of the survey items and response data about resident attitudes about their training in emergency psychiatry are presented in Table 2.

\section{Comfort and Confidence Managing Psychiatric Patients}

Only $6 \%$ of residents reported feeling quite or extremely comfortable independently performing the assessment and prescribing initial treatment for patients with psychobehavioral conditions. A minority of residents (36\%) believed that their attendings are quite or extremely comfortable treating patients with psychobehavioral conditions. Residents' self-reported confidence performing various clinical skills related to emergency psychiatric care ranged from 0 (cannot do at all) to 100 (highly certain can do). On average, most residents rated their level of confidence performing various skills related to emergency psychiatric care in the moderate range $($ mean $=60)$. As expected, confidence levels generally increased by PGY; however, this was not always the case among PGY-4s whose confidence ratings were lower than the mean across several skill areas. A one-way between-groups analysis of variance was performed to investigate the impact of PGY level on levels of confidence. There was a significant difference in overall (average) confidence scores by PGY level $(\mathrm{F}(3,364)=12.4, \mathrm{p}<0.001)$. Post hoc analyses using the Tukey HSD test indicated that the mean score for PGY-1s (mean $\pm \mathrm{SD}=50.64 \pm 17.4$ ) was significantly lower than PGY-2s (mean $\pm \mathrm{SD}=$ $61.42 \pm 17.8)$, and PGY-3s (mean $\pm \mathrm{SD}=$ $63.94 \pm 16.40$ ). Supplemental analyses were also performed to examine differences in confidence levels among residents who had completed a psychiatry rotation during residency versus those who had not completed a psychiatry rotation. Surprisingly, residents 
Table 2

Resident Attitudes About Training in Emergency Psychiatry

\begin{tabular}{|c|c|c|c|c|c|c|c|}
\hline Item & Total $N$ & $\begin{array}{l}\text { Mean }( \pm S D) \\
\text { Median }\end{array}$ & $1^{\dagger}$ & $2^{\dagger}$ & $3^{\dagger}$ & $4^{\dagger}$ & $5^{\dagger}$ \\
\hline $\begin{array}{l}\text { How much do you think you need to } \\
\text { learn or improve in each of the } \\
\text { following topic areas? }\end{array}$ & & & Nothing & $\begin{array}{l}\text { A small } \\
\text { amount }\end{array}$ & $\begin{array}{l}\text { A moderate } \\
\text { amount }\end{array}$ & $\begin{array}{l}\text { A large } \\
\text { amount }\end{array}$ & $\begin{array}{l}\text { A very large } \\
\text { amount }\end{array}$ \\
\hline Medically clearing psychiatric patients & 388 & $2.46( \pm 1.1), 3$ & $10.3(40)$ & $37.6(146)$ & $29.4(114)$ & $15.5(60)$ & $7.2(28)$ \\
\hline $\begin{array}{l}\text { Performing a mental status } \\
\text { examination }\end{array}$ & 387 & 2.61 ( \pm 1.0$), 3$ & $5.4(21)$ & $34.4(133)$ & $37.5(145)$ & $16.5(64)$ & $6.2(24)$ \\
\hline $\begin{array}{l}\text { Risk assessment of harm to self or } \\
\text { others }\end{array}$ & 388 & 2.69 ( \pm 1.0$), 3$ & $5.4(21)$ & $34.5(134)$ & $33.0(128)$ & $19.8(77)$ & $7.2(28)$ \\
\hline Lethal means counseling & 387 & $3.23( \pm 1.0), 3$ & $2.8(11)$ & $21.4(83)$ & $33.9(131)$ & $26.6(103)$ & $15.2(59)$ \\
\hline Safety planning with suicidal patients & 388 & $3.23( \pm 1.0), 3$ & $2.3(9)$ & $14.7(57)$ & $41.0(159)$ & $27.8(108)$ & $14.2(55)$ \\
\hline Etiologies of altered mental status & 388 & $3.15( \pm 1.1), 3$ & $7.7(30)$ & $37.9(147)$ & $27.6(107)$ & $16.5(64)$ & $10.3(40)$ \\
\hline Use of chemical restraints & 388 & $3.15( \pm 1.1), 3$ & $5.2(20)$ & $37.9(147)$ & $24.7(96)$ & $21.4(83)$ & $10.8(42)$ \\
\hline Acutely agitated or psychotic patient & 388 & $3.00( \pm 1.1), 3$ & $4.6(18)$ & $32.2(125)$ & $33.0(128)$ & $19.6(76)$ & $10.6(41)$ \\
\hline $\begin{array}{l}\text { Psychiatric emergencies in pregnant } \\
\text { women }\end{array}$ & 388 & $3.62( \pm 0.9), 4$ & $0.5(2)$ & $8.8(34)$ & $37.1(144)$ & $32.5(126)$ & $21.1(82)$ \\
\hline Psychiatric emergencies in the elderly & 388 & $3.38( \pm 0.9), 3$ & $0.8(3)$ & $17.0(66)$ & $42.5(165)$ & $26.3(102)$ & $13.4(52)$ \\
\hline Psychiatric emergencies in children & 388 & $3.38( \pm 0.9), 3$ & $0.5(2)$ & $15.7(61)$ & $37.1(144)$ & $30.2(117)$ & $16.5(64)$ \\
\hline $\begin{array}{l}\text { Comfort assessing and treating } \\
\text { psychiatric patients }\end{array}$ & & & $\begin{array}{l}\text { Not at all } \\
\text { comfortable }\end{array}$ & $\begin{array}{l}\text { Mildly } \\
\text { comfortable }\end{array}$ & $\begin{array}{l}\text { Somewhat } \\
\text { comfortable }\end{array}$ & $\begin{array}{l}\text { Quite } \\
\text { comfortable }\end{array}$ & $\begin{array}{l}\text { Extremely } \\
\text { comfortable }\end{array}$ \\
\hline $\begin{array}{l}\text { If there were no psychiatrist in your } \\
\text { institution, how comfortable would } \\
\text { you feel performing the assessment } \\
\text { and prescribing initial treatment for } \\
\text { psychiatric patients by yourself? }\end{array}$ & 373 & $2.00( \pm 0.9), 2$ & $38.9(145)$ & $35.7(133)$ & $19.3(72)$ & $5.9(22)$ & $0.3(1)$ \\
\hline $\begin{array}{l}\text { Importance of developing } \\
\text { competence to assess and treat } \\
\text { psychiatric patients }\end{array}$ & & & $\begin{array}{l}\text { Not at all } \\
\text { important }\end{array}$ & $\begin{array}{l}\text { Mildly } \\
\text { important }\end{array}$ & $\begin{array}{r}\text { Somewhat } \\
\text { important }\end{array}$ & $\begin{array}{l}\text { Quite } \\
\text { important }\end{array}$ & $\begin{array}{l}\text { Extremely } \\
\text { important }\end{array}$ \\
\hline $\begin{array}{l}\text { How important is it for you to } \\
\text { develop competency in the } \\
\text { assessment and treatment of } \\
\text { patients with psychiatric complaints? }\end{array}$ & 385 & $3.69( \pm 0.9), 4$ & $1.6(6)$ & $7.8(30)$ & $21.6(83)$ & $43.9(169)$ & $25.2(97)$ \\
\hline $\begin{array}{l}\text { Preparedness assessing and treating } \\
\text { psychiatric patients }\end{array}$ & & & $\begin{array}{l}\text { Not at all } \\
\text { prepared }\end{array}$ & $\begin{array}{l}\text { Mildly } \\
\text { prepared }\end{array}$ & $\begin{array}{l}\text { Somewhat } \\
\text { prepared }\end{array}$ & $\begin{array}{l}\text { Quite } \\
\text { prepared }\end{array}$ & $\begin{array}{l}\text { Extremely } \\
\text { prepared }\end{array}$ \\
\hline $\begin{array}{l}\text { How prepared are you to assess and } \\
\text { treat patients presenting with } \\
\text { psychiatric chief complaints? }\end{array}$ & 385 & 2.61 ( \pm 0.9$), 3$ & $9.6(37)$ & $32.7(126)$ & $43.9(169)$ & $12.7(49)$ & $1.0(4)$ \\
\hline
\end{tabular}

Numbers may not sum to 396 because of missing data. Percentages are calculated using all available data.

SUD $=$ substance use disorders.

${ }^{\dagger}$ Data are reported as \% (No.).

${ }^{\ddagger} \mathrm{PGY}-1 \mathrm{~s}$ did not answer these items 
who had completed a psychiatry rotation during residency reported, on average, significantly lower levels of confidence (mean $\pm \mathrm{SD}=41.40 \pm 18.87$ ) compared to residents who had completed a psychiatry rotation (mean $\pm \mathrm{SD}=63.53 \pm 15.63 ; \mathrm{t}(291)=-7.83$, $\mathrm{p}<0.001)$. Specific survey items and response data related to resident attitudes about their training in emergency psychiatry are presented in Table 3.

\section{Attitudes Toward Patients With Mental Illness}

Emergency medicine residents in this study had significantly higher (more stigmatizing) scores on the Attitude Subscale of the Opening Minds Scale for Health Care Providers (mean $\pm \mathrm{SD}=13.42 \pm 3.96$ ) compared to the sample of physicians included in the development of the measure (mean $\pm \mathrm{SD}=$ $12.7 \pm 3.4 ; \mathrm{t}(1050)=3.11, \mathrm{p}=0.002)$; however, the effect size was small $(\mathrm{d}=0.195)$. As expected, the majority of residents (84\%) reported that they are more comfortable treating patients with a physical illness than a mental illness. Nonetheless, most respondents reported feeling compassionate toward patients with mental illness and believed that they could help a patient with mental illness (see Table 4).

\section{DISCUSSION}

We conducted a needs assessment using a sample of 15 EM residency programs across the U.S. to gather information about EM resident exposure to education regarding psychobehavioral conditions, perceived confidence treating patients with such conditions, and perceived educational needs with regard to psychobehavioral conditions. Overall, we found that the focus on psychobehavioral conditions in EM residency education is relatively minimal compared to the frequency with which these conditions are encountered clinically. Consequently, most EM residents feel uncomfortable and lack confidence independently managing patients with psychobehavioral conditions and would like more training in this area.

Our survey results also demonstrated that opportunities for ongoing dedicated educational experiences managing patients with psychobehavioral conditions are rather limited, possibly in part due to a greater emphasis placed on teaching the management of medical and surgical conditions. The ACGME EM Program Requirements do not specifically mention that residents should be able to competently evaluate and provide initial treatment for patients with psychobehavioral conditions. ${ }^{6}$ Instead, these requirements place a heavy emphasis on the importance of residents developing medical and surgical procedural competencies. ${ }^{6}$ To meet these requirements, most programs require residents to rotate through settings designed to develop their medical and surgical procedural skills including obstetrics and gynecology, medical, surgical and pediatric intensive care units, trauma and acute care surgery, and anesthesiology. Nearly all (>99\%) of respondents completed a psychiatry rotation during medical school, but only $12 \%$ reported rotating through a psychiatry rotation in residency. Not surprisingly, the vast majority (84\%) of respondents agreed or strongly agreed that they feel more comfortable managing a patient with a physical illness than a MH illness. The relatively limited opportunity for ongoing dedicated educational experiences managing patients with psychobehavioral conditions may be one reason why EM residents have less confidence in this area when compared to managing patients with medical or surgical conditions.

We found that most residents would prefer more education on managing psychobehavioral conditions through various methods including lectures, simulation, and hands on training in the ED. Review of the EM literature demonstrated a paucity of data surrounding the best methods for teaching psychobehavioral emergencies. The use of high-fidelity simulation followed by structured group debriefs has previously been well received by psychiatry residents and nurses learning how to manage psychobehavioral conditions. ${ }^{17-19}$ Teaching strategies using standardized patients and role-playing have also been found to increase learner comfort with assessing and managing psychobehavioral conditions. ${ }^{20,21}$ In medical students, case-based independent study was found to be an effective method to improve exposure to emergency psychiatry cases and could be adapted for resident use. $^{20,22}$ Dedicated off-service emergency psychiatry rotations could also be developed to address educational needs. ${ }^{23}$ MacLean et al. ${ }^{24}$ previously described learning objectives for an off-service psychiatry rotation for EM residents, and the American Association for Emergency Psychiatry has published guidelines and a model curriculum with specific training objectives for psychiatry residents to learn emergency psychiatry that could be adapted for the EM resident. ${ }^{24,25}$ Zun $^{26}$ previously advocated for developing a fellowship in emergency psychiatry as well as a course for psychiatric 
Table 3

Resident Confidence in Psychiatric Skills

\begin{tabular}{|c|c|c|c|c|c|c|c|}
\hline Item & $\begin{array}{c}\text { Total } \\
(n=381)\end{array}$ & $\begin{array}{l}\text { PGY-1 } \\
(n=131)\end{array}$ & $\begin{array}{c}\text { PGY-2 } \\
(n=117)\end{array}$ & $\begin{array}{l}\text { PGY-3 } \\
(n=89)\end{array}$ & $\begin{array}{l}P G Y-\geq 4 \\
(n=44)\end{array}$ & $\begin{array}{c}\text { Psych } \\
\text { Rotation }(n=38)\end{array}$ & $\begin{array}{l}\text { No Psych } \\
\text { Rotation } \\
(n=261)\end{array}$ \\
\hline $\begin{array}{l}\text { Conduct an H\&P to } \\
\text { determine whether } \\
\text { psychiatric complaints } \\
\text { are due to an organic } \\
\text { or psychological cause }\end{array}$ & $65.57( \pm 23.0)$ & $56.10( \pm 25.3)$ & $67.57( \pm 21.4)$ & $73.88( \pm 16.6)$ & $71.61( \pm 22.0)$ & $51.45( \pm 25.96)$ & $71.04( \pm 18.22)$ \\
\hline $\begin{array}{l}\text { Differentiate a } \\
\text { psychiatric presentation } \\
\text { from delirium }\end{array}$ & $63.17( \pm 20.8)$ & $53.40( \pm 23.3)$ & $65.47( \pm 17.5)$ & $70.93( \pm 16.0)$ & $70.20( \pm 19.2)$ & $53.34( \pm 18.97)$ & $68.00( \pm 17.51)$ \\
\hline $\begin{array}{l}\text { Determine whether a } \\
\text { patient is at risk of } \\
\text { harm to self or others }\end{array}$ & $69.97( \pm 21.1)$ & $62.70( \pm 23.6)$ & $72.86( \pm 19.2)$ & $75.61( \pm 17.4)$ & $72.61( \pm 19.3)$ & $60.05( \pm 19.90)$ & $74.48( \pm 17.49)$ \\
\hline $\begin{array}{l}\text { Develop a safety plan } \\
\text { with a suicidal patient }\end{array}$ & $46.21( \pm 25.2)$ & $44.32( \pm 22.9)$ & $47.56( \pm 26.3)$ & $48.34( \pm 26.1)$ & $43.63( \pm 27.0)$ & $23.22( \pm 26.68)$ & $51.48( \pm 23.40)$ \\
\hline $\begin{array}{l}\text { Counsel a suicidal } \\
\text { patient about reducing } \\
\text { access to firearms and } \\
\text { other lethal means }\end{array}$ & $51.11( \pm 26.8)$ & $47.06( \pm 24.7)$ & $54.75( \pm 27.5)$ & $53.84( \pm 27.1)$ & $47.19( \pm 28.9)$ & $23.24( \pm 24.89)$ & $56.76( \pm 23.60)$ \\
\hline $\begin{array}{l}\text { Initiate treatment for } \\
\text { patients presenting with } \\
\text { drug overdose }\end{array}$ & $67.24( \pm 25.0)$ & $55.45( \pm 24.4)$ & $71.57( \pm 22.7)$ & $75.31( \pm 22.9)$ & $74.52( \pm 24.6)$ & $56.61( \pm 23.60)$ & $73.62( \pm 21.32)$ \\
\hline $\begin{array}{l}\text { Perform the assessment } \\
\text { and prescribe initial } \\
\text { treatment of the acutely } \\
\text { agitated or psychotic } \\
\text { patient }\end{array}$ & $63.02( \pm 24.2)$ & $47.88( \pm 23.1)$ & $68.50( \pm 21.1)$ & $72.18( \pm 19.7)$ & $74.59( \pm 21.7)$ & $66.97( \pm 20.57)$ & $67.73( \pm 22.46)$ \\
\hline $\begin{array}{l}\text { Perform the assessment } \\
\text { and prescribe initial } \\
\text { treatment of pregnant } \\
\text { women with psychiatric } \\
\text { complaints }\end{array}$ & $40.78( \pm 24.5)$ & $32.77( \pm 20.9)$ & $44.79( \pm 25.3)$ & $44.96( \pm 24.6)$ & $44.41( \pm 26.7)$ & $21.45( \pm 20.14)$ & $46.41( \pm 24.02)$ \\
\hline $\begin{array}{l}\text { Perform the assessment } \\
\text { and prescribe initial } \\
\text { treatment of elderly } \\
\text { patients with } \\
\text { psychiatric complaints }\end{array}$ & $49.69( \pm 24.7)$ & $42.27( \pm 20.5)$ & $52.98( \pm 25.1)$ & $54.27( \pm 25.0)$ & $52.61( \pm 29.3)$ & $26.55( \pm 25.54)$ & $55.90( \pm 22.65)$ \\
\hline $\begin{array}{l}\text { Perform the assessment } \\
\text { and prescribe initial } \\
\text { treatment of children } \\
\text { with psychiatric } \\
\text { complaints }\end{array}$ & $42.55( \pm 24.7)$ & $33.96( \pm 20.3)$ & $45.49( \pm 25.0)$ & $47.48( \pm 24.9)$ & $49.33( \pm 28.9)$ & $23.89( \pm 22.47)$ & $48.29( \pm 24.13)$ \\
\hline
\end{tabular}

Data are reported as mean $( \pm S D)$. Psych Rotation refers to residents who completed a psychiatry rotation during and EM or non-EM residency. No psych rotation refers to those residents who did not complete a psychiatry rotation during residency.

$\mathrm{H} \& \mathrm{P}=$ history and physical examination. 


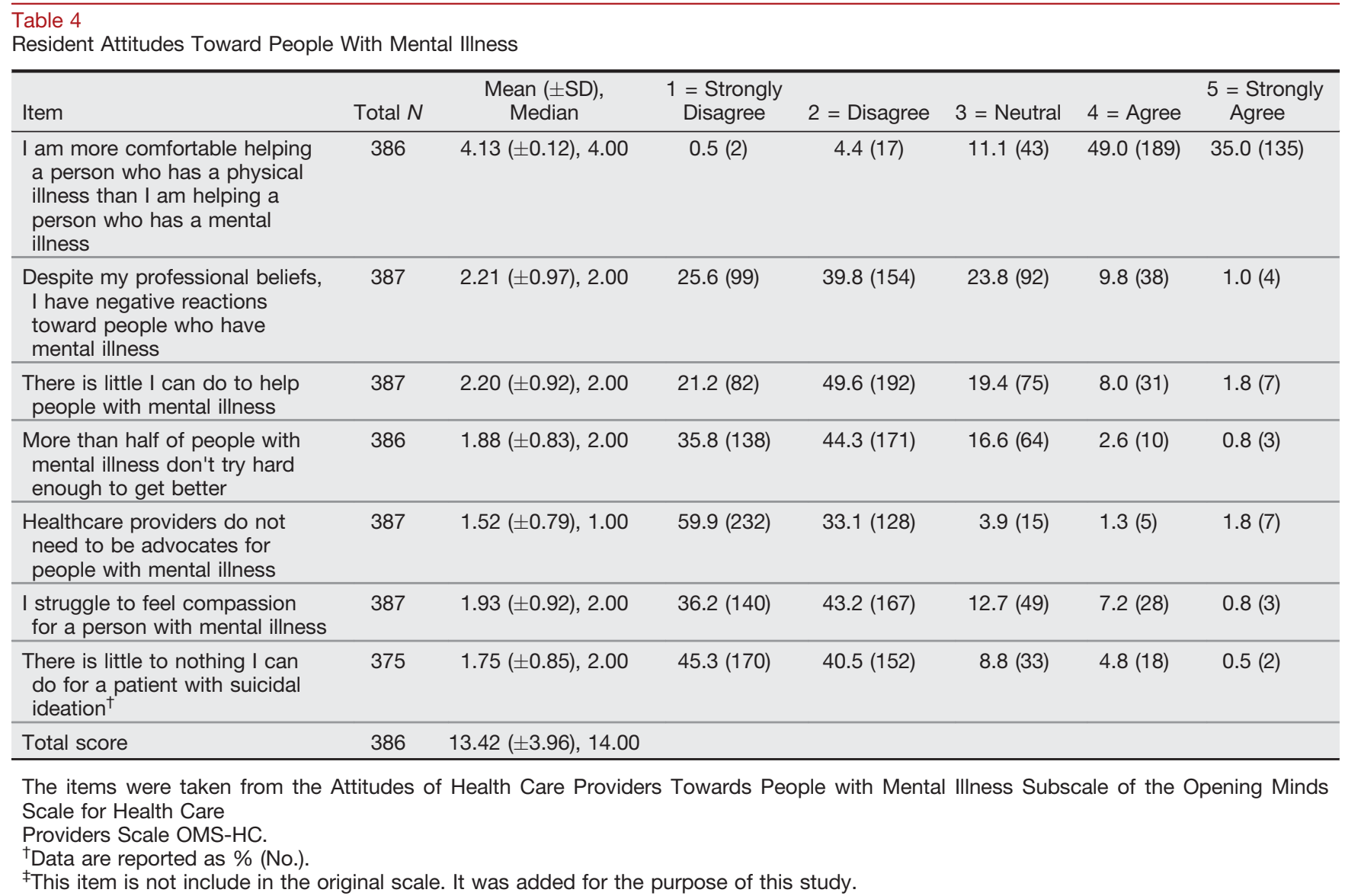

emergencies similar to advanced trauma life support, advanced cardiovascular life support, and pediatric advanced life support. Increased bedside teaching of concepts related to evaluation and management of psychobehavioral conditions by experienced EM attendings may also promote hands-on resident learning on shift.

Opportunities to learn through hands-on training in the ED are available given that all residents reported typically seeing at least one or more patients with a psychobehavioral chief complaint during a typical 8-hour shift. Nonetheless, over half of respondents described minimal involvement with psychiatric patients. Residents reported that only about one-third of their attendings are quite or extremely comfortable treating these patients, which may explain why educational discussions on these patients are not occurring. Furthermore, EM residents may be taking a less active role in the care of patients with psychobehavioral conditions due to the availability of consultants, social workers, or other support services. While this may not pose a problem in an academic medical setting with access to psychiatric consultants and other support services, many residents will go on to practice in rural or lower-resource settings that offer limited additional support. Thus, ensuring that residents feel confident independently managing these patients through increased autonomy and involvement in their care is critical to successful practice in diverse environments upon completion of training.

The results of our study showed that residents who completed a psychiatry rotation actually reported lower levels of confidence performing various clinical skills related to psychobehavioral conditions compared to residents who had not completed a psychiatry rotation. These results were initially surprising; however, it may be that after completing a psychiatry rotation residents had developed a greater understanding of the skills and amount of training needed to effectively treat patients with psychobehavioral conditions. It is also important to note that physician self-reported levels of confidence are often poor predictors of observational measures of performance. In fact, several studies have found that that physicians who are the least skilled are often the most confident and least likely to recognize their learning needs. ${ }^{27}$ Given these implications, future studies examining residents' training needs would benefit from including objective measures of performance in addition to self-assessments. 
Our study identified several specific content areas within the broader category of psychobehavioral conditions in which residents wish to improve their knowledge and skills: 1) management in special populations such as pregnant women, children, and elderly patients; 2) lethal means counseling; and 3) safety planning with suicidal patients. Correspondingly, residents expressed the lowest confidence levels with performing the assessment and prescribing initial treatment of special populations. Simulation exercises and didactic content could target these identified areas of need. The current lack of a clear "best practices" guide for training methods may account for the survey results demonstrating that the amount of time spent and the method of training in psychobehavioral conditions are widely variable among residency programs. Residency programs would benefit from an improved and more standardized curriculum.

\section{LIMITATIONS}

There are several limitations of this study. First, participants were a convenience sample of EM residents from 15 ACGME-accredited EM programs that were identified based on existing professional relationships. We did not systematically include residents from programs with varying levels of emergency psychiatric services (e.g., availability of consultants, dedicated psychiatric emergency unit) and resident educational offerings (e.g., required psychiatry rotation). However, by limiting participating programs to those with known colleagues available to help with data collection, we were able to maximize our response rate, which was rather high especially for a survey study. Additionally, we were able to include residents completing programs in all areas of the United States. A second concern involved the timing of data collection (July and August). Early in the academic year, the PGY-1s would have little experience and contact with patients. While patients presenting with psychobehavioral complaints and subsequent boarding of these patients are increasing, patient presentations can vary seasonally. Changing the survey timing may alter responses for both junior and senior residents.

\section{CONCLUSIONS}

In summary, residents in emergency medicine desire more training in the management of psychobehavioral conditions. There are wide variations among residency programs with regard to the time spent in training and the methods of training for psychobehavioral conditions. Residency programs would benefit from more education in psychobehavioral conditions and a clear set of best practices for improved curriculum standardization.

We thank Alicia Pilarski, MD, Nicholas Schwartz, MD, Robert Cooney, MD, Andy Grock, MD, Kyle Ragins, MD, Steven Hochman, MD, and Loice Swisher, MD for their help with data collection.

\section{References}

1. Center for Behavioral Health Statistics and Quality. Behavioral health trends in the United States: results from the 2014 national survey on drug use and health. HHS Publication No. SMA 15-4927, NSDUH Series H-50. 2015. at https://www.samhsa.gov/data/sites/default/files/NSDUHFRR1-2014/NSDUH-FRR1-2014.pdf. Accessed October 12, 2018.

2. Owens PL, Mutter R, Stocks C. Mental Health and Substance Abuse-related Emergency Department Visits Among Adults, 2007. Healthcare Cost and Utilization Project (HCUP) Statistical Brief \#92. 2010. Available at: http:// www.hcup-us.ahrq.gov/reports/statbriefs/sb92.pdf.

Accessed November 1, 2018.

3. Moore BJ, Stocks C, Owens PL. Trends in Emergency Department Visits, 2006-2014. Healthcare Cost and Utilization Project (HCUP) Statistical Brief \#227. 2017. Available at: www.hcup-us.ahrq.gov/reports/statbriefs/sb 227-Emergency-Department-Visit-Trends.pdf. Accessed November 2, 2018.

4. Nicks BA, Manthey DM. The impact of psychiatric patient boarding in emergency departments. Emerg Med Int 2012;2012:1-5.

5. American College of Emergency Physicians. Definition of Emergency Medicine. Policy Compendium. 2015. Available at: http://www.acep.org/workarea/DownloadAsset.a spx?xml:id=101698. Accessed November 10, 2018.

6. Accreditation Council for Graduate Medical Education (ACGME). ACGME Common Program Requirements (Residency). 2018. Available at: https://www.acgme.org/ Portals/O/PFAssets/ProgramRequirements/CPRResidenc y2019.pdf. Accessed November 6, 2018.

7. Counselman FL, Babu K, Edens MA, et al. The 2016 Model of the Clinical Practice of Emergency Medicine. J Emerg Med 2017;52:846-9.

8. Santucci KA, Santher J, Baker DM. Emergency medicine training programs' educational requirements in the management of psychiatric emergencies. Pediatr Emerg Care 2003;19:154-6.

9. American Board of Emergency Medicine (ABEM). Qualifying Exam Content Specifications. Available at: https:// 
www.abem.org/public/become-certified/qualifying-exam/ exam-content. Accessed November 8, 2018.

10. Tintinalli JE, Stapczynski JS, Ma OJ, Yealy DM, Meckler GD, Cline DM. Tintinalli's Emergency Medicine: A Comprehensive Study Guide, 8th ed. New York: McGraw-Hill, 2016.

11. Walls R, Hockberger R, Gausche-Hill M. Rosen's Emergency Medicine: Concepts and Clinical Practice, 8th ed. Philadelphia: Elsevier/Saunders, 2014.

12. Weissberg M. The meagerness of physicians' training in emergency psychiatric intervention. Acad Med 1990;65:747-50.

13. Cook DA, Blachman MJ, Price DW, West CP, Berger RA, Wittich CM. Professional development perceptions and practices among U.S. physicians. Acad Med 2017;92:1335-45.

14. American College of Emergency Physicians. The emergency physician's role in behavioral emergencies. Ann Emerg Med 1984;13:972-3.

15. Bandura A. Guide for constructing selfefficacy scales. in: Pajares F, Urdan T, eds. Self-Efficacy Beliefs of Adolescents. Greenwich, CT: Information Age Publishing, 2006:307-38.

16. Kassam A, Papish A, Modgill G, Patten S. The development and psychometric properties of a new scale to measure mental illness related stigma by health care providers: the Opening Minds Scale for Health Care Providers (OMS-HC). BMC Psychiatry 2012;12:1-12.

17. Masters J, Kane M, Pike M. The suitcase simulation: an effective and inexpensive psychiatric nursing teaching activity. J Psychosoc Nurs Ment Health Serv 2014;52:39-44.

18. Thomson AB, Cross S, Key S, Jaye P, Iversen AC. How we developed an emergency psychiatry training course for new residents using principles of high-fidelity simulation. Med Teach 2013;35:797-800.

19. Murray BA. The use of high-fidelity simulation in psychiatric and mental health nursing clinical education. Int J Health. Sci Educ 2014;2:;Art:3.
20. Lofchy J, Boyles P, Delwo J. Emergency psychiatry: clinical and training approaches. Can J Psychiatry 2015;60:1-7.

21. Lofchy J. The use of standardized patients in the teaching of emergency psychiatry. Emerg Psychiatry 1997;3: 78-79.

22. Hirshbein LD, Gay T. Case-based independent study for medical students in emergency psychiatry. Acad Psychiatry 2005;29:96-9.

23. Bode A, Jackson JS. The current emergency medicine residency curriculum: missing psychiatry. Am J Emerg Med 2017;35:1771-2.

24. MacLean TA, Bourgeois JA, Hamilton GC, Kay J. Objectives to direct the training of emergency medicine residents on off-service rotations: psychiatry. J Emerg Med 1995;13:545-51.

25. Brasch J, Glick RL, Cobb TG, Richmond J. Residency training in emergency psychiatry: a model curriculum developed by the education committee of the American Association of Emergency Psychiatry. Acad Psychiatry 2004;28:95-103.

26. Zun L. Care of psychiatric patients: the challenge to emergency physicians. West J Emerg Med 2016;17:174-6.

27. Davis DA, Mazmanian PE, Fordis M, Van Harrison R, Thorpe KE, Perrier L. Accuracy of physician self-assessment compared with observed measures of competence: a systematic review. JAMA 2006;296:1094-102.

\section{Supporting Information}

The following supporting information is available in the online version of this paper available at http:// onlinelibrary.wiley.com/doi/10.1002/aet2.10377/full

Data Supplement S1. Resident program characteristics. 